\title{
Is blood transfusion really needed in living-donor liver transplant?
}

Medrano P., Hidalgo F., López L., Chiquito M.T., Hernando B., Bercianos E. Clinica Universidad de Navarra, Departament of Anaesthesiology \& Intensive Care, Pamplona, Spain

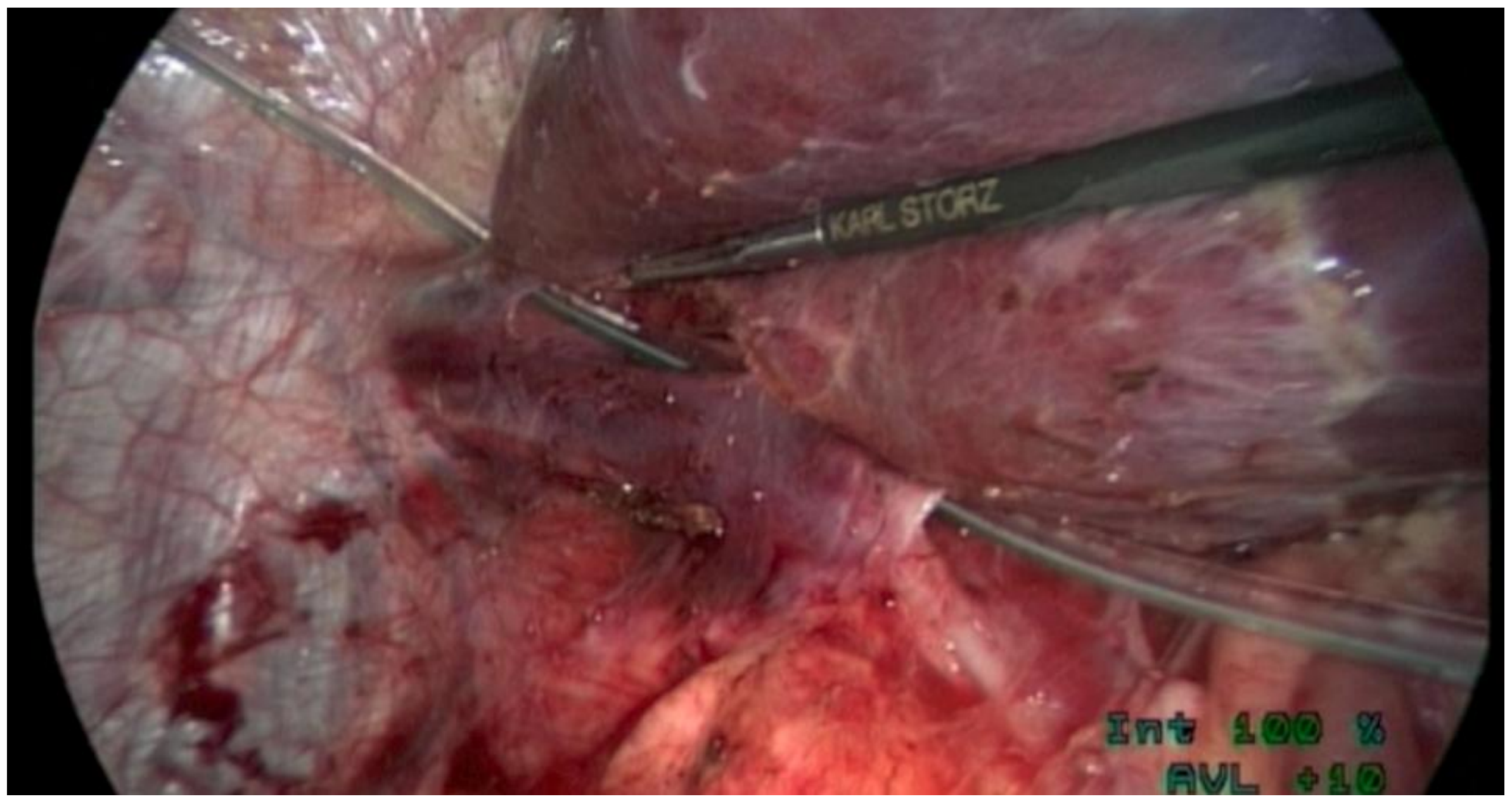

\section{Goal of study:}

Patients undergoing hepatectomy have potential risk of extensive bleeding and blood transfusion requirements, that correlates with postoperative morbidity and mortality.

In case of living donor liver transplantation (LDLT) it is essential to reduce complications during the intervention at all levels, because most of the donors are healthy. Therefore, reduction of transfusion requirements, and especially restrict the use of allogeneic blood is a essential part of this strategy.

The objective of this study is to determine the efficacy, safety and effectiveness of autotransfusion in each technique.

\section{Materials and methods:}

26 patients between 2003 and 2015 undergoing surgery as donors in LDLT were analyzed retrospectively. In all cases a combination of saving techniques were used: preoperative blood donation, intraoperative recovery systems and acute isovolemic hemodilution (AlH).

We analyzed transfusion requirements and laboratory results; the associated complications of each technique were also reviewed.

\section{Results:}

The average age was $34.11(+/-9.35)$ years with a $50 \%$ female population. The duration of surgery was $10,79(+/-2.8)$ hours with an average clamping time of $92.92+/-31.32 \mathrm{~min}$. Lastly, the baseline hemoglobin was $13.2(+/-1.4)$.

During these years, we have observed a decreased in transfusion requirements and parallel we have decreased the preoperative blood donation. We made 12 made preoperative blood donation with 2 blood units and 1 or 2 plasmapheresis. Next 8 pacients donated 1 blood unit and 1 or 2 plasmapheresis and the remaining 6 just made preoperative hemodonation with 1 blood unit.

The following table (1) shows transfusion requirements:

\begin{tabular}{|c|c|}
\hline TRANSFUSION & PATIENTS 26 \\
\hline NO & $6(23 \%)$ \\
\hline Autologous AIH & $20(76.92 \%)$ \\
\hline Autologous preoperative & $7(26.92 \%)$ \\
\hline Autologous CellSaver & $1(3.84 \%)$ \\
\hline Heterologous & $1(3.84 \%)$ \\
\hline
\end{tabular}

Table (2):

\begin{tabular}{|c|c|c|c|c|}
\hline & Basal & $\mathrm{ICU}$ & $24 \mathrm{H}$ & HDR \\
\hline $\mathrm{Hb}$ & $\begin{array}{c}13.32+/- \\
1.4\end{array}$ & $\begin{array}{c}11.9+/- \\
1.3\end{array}$ & $\begin{array}{c}11+/- \\
1.11\end{array}$ & $\begin{array}{c}11.2+/- \\
1.03\end{array}$ \\
\hline Platelets & $\begin{array}{c}25410^{3}+/- \\
6810^{3}\end{array}$ & $\begin{array}{c}22310^{3}+/- \\
4910^{3}\end{array}$ & $\begin{array}{c}19710^{3}+/- \\
4410^{3}\end{array}$ & $\begin{array}{c}21210^{3}+/ \\
8210^{3}\end{array}$ \\
\hline PT & $\begin{array}{c}11.48+/- \\
0.89\end{array}$ & $\begin{array}{c}13.29+/- \\
0.78\end{array}$ & $\begin{array}{c}15.69+/- \\
1.65\end{array}$ & $\begin{array}{c}13.65+/- \\
2.01\end{array}$ \\
\hline APTT & $31.72+/-3.4$ & $\begin{array}{c}29.76+/- \\
2.95\end{array}$ & $\begin{array}{c}36.68+/- \\
3.09\end{array}$ & $\begin{array}{c}32.19+/- \\
3.79\end{array}$ \\
\hline Fibrinog. & $311+/-64$ & $260+/-63$ & $257+/-56$ & $342+/-59$ \\
\hline
\end{tabular}

HDR: Last analysis before Hospital discharge report. PT: Prothrombin time. APTT: Activated partial thromboplatin time.

Of all patients analyzed only 3 of them required postoperative transfusion and only one patient required heterologous blood.

We found no differences between the analytical parameters (Hemoglobin, platelets, PT, APTT and fibrinogen) according to their blood requirements.

\section{Discussion and conclusions:}

Although it is difficult to estimate blood loss, we found a decreasing blood products requirements which may be due to an increased experience and improved surgical techniques.

Most patients require the administration of blood products intraoperatively and autologous transfusion eliminates the risks of allogeneic blood.

The combination of preoperative donation and acute isovolemic hemodilution are revealed as the most effective method.

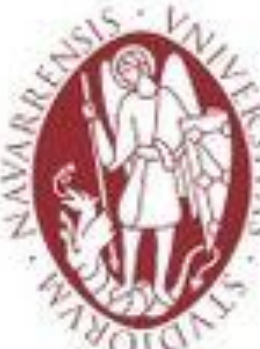

